\title{
Is an Increasing Capital Share under Capitalism Inevitable?
}

\section{Yew-Kwang NG}

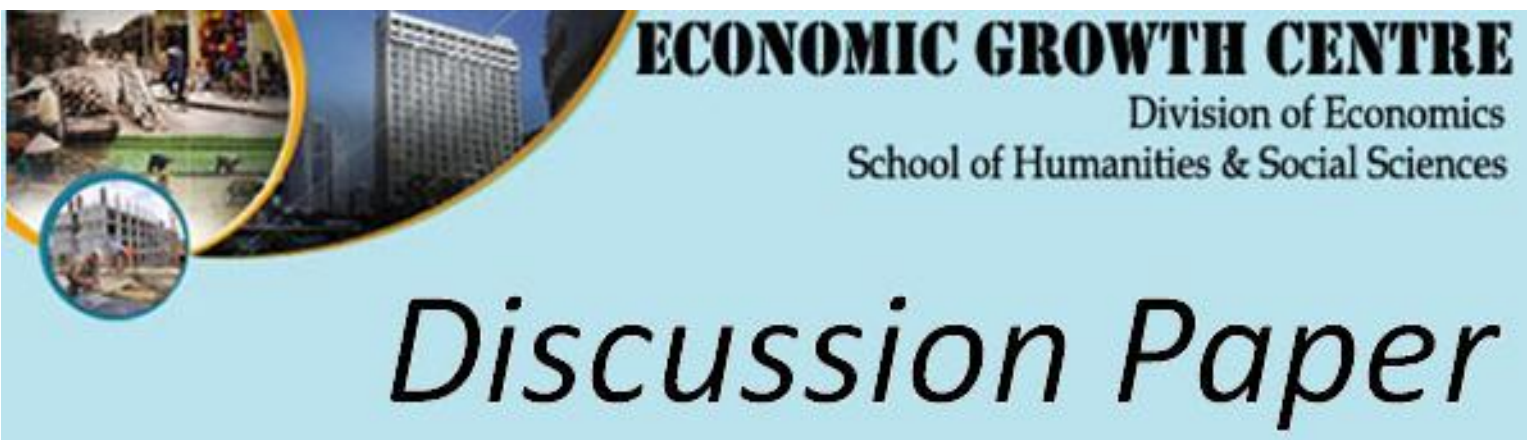


The author(s) bear sole responsibility for this paper.

Views expressed in this paper are those of the author(s) and not necessarily those of the Economic Growth Centre, NTU. 


\title{
Is an Increasing Capital Share under Capitalism Inevitable? ${ }^{1}$
}

\author{
Yew-Kwang Ng \\ Winsemius Professor, Division of Economics, Nanyang Technological University, \\ 14 Nanyang Drive, Singapore 637332. Phone: 65-67906785; email: ykng@ntu.edu.sg \\ [Emeritus Professor, Monash University. Kwang.ng@monash.edu ]
}

\begin{abstract}
Piketty's influential book Capital in the Twenty-First Century and its prominent review by Milanovic in the Journal of Economic Literature both assert the inevitability of an increasing share of capital in total income, given a higher rate of return to capital than the rate of growth in income. This paper shows by a specific example, a logical argument and its intuition that the alleged inevitability is not valid. Even just for capital to grow faster than income, we need an additional requirement that saving of non-capital income is larger than consumption of capital income. Even if this is satisfied, the capital share may not increase as the rate of return may fall and non-capital incomes may increase with capital accumulation.
\end{abstract}

JEL Codes: D3, P1.

Keywords: capital; capitalism; distribution; income; wealth.

${ }^{1}$ I wish to acknowledge the research funding from Nanyang Technological University and the research assistantship of Ernie Chen Enjiao. 
Capital in the Twenty-First Century, April 2014 (French edition Le capital au $21^{e}$ siècle, 2013), the magnum opus of the renowned French economist Thomas Piketty has caused a sensation. Apart from extensive reports in the popular press, it has been quickly and prominently reviewed by Branko Milanovic in the Journal of Economic Literature as early as June 2014. This note shows that both the book and the review got an important relationship wrong, making the alleged inevitability of an increasing capital share (in income) under a higher rate of return to capital than the rate of growth in income invalid. Even just for capital to grow faster than income, we need an additional requirement that saving in non-capital income is larger than consumption of capital income. Even if this is satisfied, the capital share may not increase as the rate of return may fall and non-capital incomes may increase with capital accumulation.

\section{The Inevitable Increase in Capital Share under Capitalism?}

The current concern with inequality is related to the big increases in the degrees of inequality in income and wealth distribution after the 'golden age' of capitalism in 1945-1975. Piketty regards the period leading to the golden age with decreasing degrees of inequality as abnormal; the norm is for increasing inequality under capitalism. This note shows that this basic thesis is partly based on an incorrect logical deduction. Milanovic also queries some arguments supporting this thesis, but he and Piketty have got a basic relationship incorrect. As argued below, the capital share may either increase or decrease and a market economy may become more or less unequal, even under conditions satisfying Piketty's requirements, depending on how various opposing forces offset each other. 
The basic point of Piketty's 'new theory of capital' is very simple. He focuses on the ratio of incomes of capital $\mathrm{K}$ (which is defined more in the sense of wealth, as correctly pointed out by Milanovic, since items like land and intellectual property are included) or $\mathrm{Y}^{\mathrm{K}}$ as a proportion $\alpha$ of total income $\mathrm{Y}$; i.e. $\alpha \equiv \mathrm{Y}^{\mathrm{K}} / \mathrm{Y}$. His main point is that this ratio will increase with the development of capitalism and even approaches one, leading to most incomes going to the capitalists, unless offset by government intervention. This astonishing conclusion is very simply, but not quite correctly, derived.

Denote/define the (average) rate of return to capital as $\mathrm{r} \equiv \mathrm{Y}^{\mathrm{K}} / \mathrm{K}$ and the (average) capital/output ratio $\beta(\equiv \mathrm{K} / \mathrm{Y})$, where $\mathrm{Y}^{\mathrm{K}}$ is capital income, $\mathrm{K}$ is the value of capital, and total (real) output and total income are equal and both denoted as Y. We then have the important (for Piketty's argument) identity (called the 'first fundamental law of capitalism') for the share of income from capital in national income (called here as 'capital share' for short), denoted as $\alpha\left(\equiv \mathrm{Y}^{\mathrm{K}} / \mathrm{Y}\right)$ :

(1) $\alpha=r \times \beta$

This is an identity as from the definitions of $r$ and $\beta$, their multiplication gives $\mathrm{Y}^{\mathrm{K}} / \mathrm{Y}$ which is the definition of $\alpha$. Piketty focuses on this capital share $\alpha$ and argues that it is in the nature of capitalism for this share to increase over time, at least under the normal condition (shown to hold historically except the period leading to the golden age and argued to be likely true for the future) that the rate of return to capital $r$ is larger than the rate of growth $g$ in national income. The higher capital share is then related to inequality through the fact that the rich tend to have higher proportions of incomes from capital than the poor. (This channel may also have some complications but they are not the main concern of this note, except a relevant remark at the end of Section 2.)

In the words of Piketty, 'The inequality $r>g$ implies that wealth accumulated in the past grows more rapidly than output and wages. This inequality 
expresses a fundamental logical contradiction. The entrepreneur inevitably tends to become a rentier, more and more dominant over those who own nothing but their labor. Once constituted, capital reproduces itself faster than output increases. The past devours the future. The consequences for the long-term dynamics of the wealth distribution are potentially terrifying' (p. 399). This unfortunate outcome is inevitable under capitalism except through government intervention like taxing capital incomes.

In the words of Milanovic, 'Now, if the rate of return on capital remains permanently above the rate of growth of the economy $(g)$-this is Piketty's key inequality relationship $r>g$-then $\alpha$ increases by definition. This, combined with the increasing $\beta$, drives the share of capital in national income arbitrarily close to one’ (p. 522). Capital takes increasingly more and eventually almost all!

Moreover, 'The process has a positive feedback loop: as $\alpha$ increases, not only do capital owners become richer, but, unless they consume the entire return from their capital, more will remain for them to reinvest. The increased saving in turn makes the growth rate of capital exceed further the growth rate of national income and raises $\beta$. Thus, not only does higher $\beta$ lead to higher $\alpha$ but higher $\alpha$ leads to higher $\beta$.’ (Milanovic 2014, p. 522).

From equation (1), one can easily see that if the capital-output ratio $\beta$ increases with capital accumulation, capital share $\alpha$ must increase unless the rate of return $\mathrm{r}$ falls proportionately more as a result. Piketty shows with data that $\mathrm{r}$ did not fall substantially but remained typically at around 4-5\%. More importantly, both Piketty and Milanovic believe that, logically, the condition of $r>g$ is sufficient for the capital share to increase over time. This is the crucial point challenged in the next section. 


\section{The Inevitability Logic Challenged}

A numerical example of non-inevitability even under conditions satisfying all Piketty's requirements is first given, before an intuitive explanation and a more general mathematical demonstration.

Our counter example to the Piketty-Milanovic inevitability of increasing capital share under the condition of $r>g$ is shown in Table 1. Though the table shows only three periods for simplicity, it could be extended indefinitely without changing the result of a decreasing capital share $\alpha$ under conditions satisfying all the Piketty-Milanovic requirements. As illustrated in Table 1, the economy has a capital value of 200 in period 1 , and output of 100 , giving a capital-output ratio $\beta$ of 2 . This ratio is taken to be unchanged throughout, as is true also for the growth rate $g$ at $10 \%$ and saving rate $\mathrm{s}$ at $20 \%$. Thus, these figures are also consistent with Piketty's requirement that in the long run, $\beta=\mathrm{s} / \mathrm{g}$ approximately. Capital income $\mathrm{Y}^{\mathrm{K}}$ is given by $\mathrm{rK}$ (from the definition of $\mathrm{r}$ ) and equals 40 in period 1, giving the capital share at $40 \%$. The increase in capital $\mathrm{K}$ over time is given by sY, as income and saving are defined to be already net of deduction for capital depreciation. There is nothing in the Pikketty-Milanovic requirements to prevent the rate of return $r$ from decreasing with the accumulation of capital over time. Thus, we allow $r$ to decrease by a decreasing amount each period after the first and approaches $11 \%$ asymptotically. More exactly, the value of $\mathrm{r}$ equals $0.11+0.1$ $(0.9)^{t}$, for each period $t=1,2,3, \ldots$. Thus, $r$ remains permanently above g by at

least a full percentage point, more than satisfying $r>$ g. Yet, the capital share $\alpha$ decreases throughout, negating the inevitability of an increasing capital share, not to mention driving it 'arbitrarily close to one'. 
Table 1 Possibility of decreasing capital share under $r>g$

\begin{tabular}{|c|c|c|c|}
\hline Period & 1 & 2 & 3 \\
\hline $\mathrm{K}$ & 200 & 220 & 242 \\
\hline $\mathrm{Y}$ & 100 & 110 & 121 \\
\hline$\beta$ & 2 & 2 & 2 \\
\hline $\mathrm{r}$ & $20 \%$ & $19.1 \%$ & $18.29 \%$ \\
\hline $\mathrm{g}$ & $10 \%$ & $10 \%$ & $10 \%$ \\
\hline $\mathrm{s}$ & $20 \%$ & $20 \%$ & $20 \%$ \\
\hline $\mathrm{Y}^{\mathrm{K}}$ & 40 & 42.02 & 44.2618 \\
\hline$\alpha$ & $40 \%$ & $38.2 \%$ & $36.58 \%$ \\
\hline
\end{tabular}

Let us now come to the intuitive explanation of the insufficiency of the Piketty-Milanovic requirements for the inevitability of an increasing capital share. These requirements are taken to be the long-term applicability of the inequality $r>$ $\mathrm{g}$, plus the long-term equality (or approximation) that $\beta=\mathrm{s} / \mathrm{g}$, plus the noncomplete consumption of capital income, plus the general features of Piketty's model like the classification of inclusive capital $\mathrm{K}$ and non-capital factors of production, which we all observe perfectly. The basic Piketty-Milanovic intuition that the inequality $r>\mathrm{g}$ is conducive to an increasing capital share is not incorrect; it is the sufficiency or inevitability ('by definition') of it that fails. Why?

The higher the rate of return to capital, the higher the capital income for any given amount of capital. Also, the slower is Y growing (the smaller is g), the easier it is for capital income to grow faster than g. These are the valid parts that are relevant for the possibility of an increasing capital share. However, there are some factors making them not sufficient to ensure inevitability. First, Piketty only 
requires that some of the capital income is saved to increase future capital. So not all of capital incomes serve this role. (However, requiring that all capital incomes are saved is not sufficient to ensure inevitability, as will be seen below.) Second, a high capital income and a higher $\mathrm{K}$ do not ensure an increasing capital share, even if non-capital or total income does not grow very fast (a low g), because a higher $\mathrm{K}$ may lower $r$ over time without making $r$ lower than $g$.

We may put the point in a somewhat different form. A high $r$ ensures (at given K) only a high capital income. This is a static concept. An increasing capital share is a dynamic concept and is not sufficiently entailed by a high $\mathrm{r}$, or by $\mathrm{r}>\mathrm{g}$. To show this more rigorously, differentiate $\alpha \equiv \mathrm{Y}^{\mathrm{K}} / \mathrm{K}$ to obtain ${ }^{2}$, after substituting in $\mathrm{g}=\mathrm{d} \mathrm{Y} / \mathrm{Y}, \mathrm{Y}^{\mathrm{K}}=\mathrm{rK}$ and the differentiation of $\mathrm{Y}^{\mathrm{K}}=\mathrm{rK}$,

\section{(2) $d \alpha / \alpha=(d K / K)+(d r / r)-g$}

This equation shows that whether the capital share is increasing or not (i.e. d $\alpha$ positive or not) depends on whether the sum of the rates of growth in $\mathrm{K}$ and in $\mathrm{r}$ is larger than $g$ or not. Since an $r$ that is larger than $g$ does not ensure that this is satisfied, the condition of $r>g$ is not sufficient to ensure an increasing capital share.

From (2), we may also see that, in order for $r>g$ to be sufficient for ensuring an increasing capital share (i.e. a positive $d \alpha$ ), we need

(3) $(\mathrm{dK} / \mathrm{K})+(\mathrm{dr} / \mathrm{r}) \geq \mathrm{r}$.

Now, we shall see that this need not hold. Consider first a simple case (to be relaxed immediately below) not ruled out by the Piketty-Milanovic requirements. Suppose all non-capital incomes are consumed and most but not all capital incomes are saved. As capital incomes equal $r K, \mathrm{~K}$ increases at a rate less than $\mathrm{r}$ (as some of $r K$ is consumed and hence $\mathrm{dK}<\mathrm{rK}$, or $\mathrm{dK} / \mathrm{K}<\mathrm{r}$ ). Thus, even if $\mathrm{r}$ is not

\footnotetext{
${ }^{2}$ The differentiation of $\alpha \equiv \mathrm{Y}^{\mathrm{K}} / \mathrm{Y}$ gives $\mathrm{d} \alpha=\mathrm{d} \mathrm{Y}^{\mathrm{K}} / \mathrm{Y}-\alpha \mathrm{g}$, where $\mathrm{g} \equiv \mathrm{dY} / \mathrm{Y}$. Divide both sides by $\alpha$, noting $\mathrm{Y}^{\mathrm{K}}=\mathrm{rK}$, and substituting out $d \mathrm{Y}^{\mathrm{K}}$ by the differentiation of $\mathrm{rK}$, we get (2) in the text.
} 
decreasing over time but just remains unchanged (i.e. $d r / r=0$ ), inequality (3) does not hold. If $r$ decreases, the result follows with a stronger force. Thus, $r>g$ does not ensure an increasing capital share. This is true even if all capital incomes are saved.

From the discussion of the previous paragraph, we may also see that, under the general framework here, a sufficient set of additional conditions, together with $r>g$, for the capital share to increase over time is for $r$ to be non-decreasing and the savings from non-capital incomes to be larger than the consumption of capital incomes. Further discussions on the likelihood of this being fulfilled and the related implications are likely to be fruitful but are beyond the scope of this note.

From (2) above the condition for an increasing capital share is not $r>g$ but $(d K / K)+(d r / r)>g$. Apart from the common $g$ in the right hand side of both these two inequalities, the left hand side of the second and correct inequality (as the condition for an increasing capital share) features the rates of change in capital $\mathrm{K}$ and its rate of return r. From this inequality, it may be thought that a high rate of capital accumulation $\mathrm{dK} / \mathrm{K}$ is conducive to an increasing capital share. This may or may not be true, because capital accumulation may decrease $r$ and increase $g$. It is useful to consider the benchmark case of a Cobb-Douglas production function (which is not assumed nor ruled out by Piketty). Here, in the absence of biased technical changes (which may be regarded as already been defined under CobbDouglas with unchanged coefficients), it is a class-room exercise to show that the capital share remains unchanged irrespective of the rate of capital accumulation. ${ }^{3}$

Even if we impose the long-run approximation of $\beta=\mathrm{s} / \mathrm{g}$, the substitution of this into (1) plus the requirement of $r>$ g only yields the result that $a>s$. Again, this only implies some relationship regarding the levels of variables, not their rates

\footnotetext{
${ }^{3}$ Given $\mathrm{Y}=\mathrm{AK}^{\theta} \mathrm{L}^{\lambda}$ (where $\mathrm{L}$ is the non-capital input) and $\mathrm{r}=\partial \mathrm{Y} / \partial \mathrm{K}$, we have $\mathrm{a}=\theta$ which remains unchanged in the absence of biased technical changes.
} 
of change over time. In particular, the capital share may be larger than the saving rate without being increasing over time, as is the case of Table 1. For that case, even if we go further than period 3 indefinitely, as $\mathrm{r}$ falls towards $11 \%$, the capital share a, being equal to $\mathrm{rK} / \mathrm{Y}$, will approach $22 \%$ (as the capital-output ratio remains at 2 in the case of Table 1), which is still larger then s, satisfying a $>$ s but with a decreasing throughout instead of increasing.

While Piketty's analysis is not confined to the special benchmark case of the Cobb-Douglas production function, it does not rule it out either. For this CobbDouglas case, the capital share is a constant. Even if unbiased technical changes are allowed, we may have growth with or without capital accumulation, with or without $r>$ g, but yet the capital share remains constant over time. That we can have persistent prevalence of $r>g$ under Cobb-Douglas (and its constancy of capital share) can easily be seen that $r$ is determined by the marginal productivity of capital which may remain reasonably high; $\mathrm{g}$ is affected both by capital accumulation and technical improvement which may both be reasonably low.

The Cobb-Douglas constancy in capital share of course needs not be true historically since biased technical changes may happen and the real world may also diverge from Cobb-Douglas. However, the possible constancy of capital share under $r>g$ shows the non-inevitability of an increasing capital share. Thus, this Cobb-Douglas example alone should be sufficient to negate the Piketty-Milanovic inevitability of an increasing capital share under $r>$ g. Essentially, the case of Cobb-Douglas (and in fact somewhat more generally) entails that an increase in $\mathrm{K}$ (capital accumulation) is offset by a decrease in the rate of return for capital and an increase in the marginal productivities of non-capital inputs, making the relative share unchanged. Going beyond Cobb-Douglas, this offset needs not be exactly to produce a constant capital share. Yet, there is no inevitability of an increasing share. Milanovic correctly raises the possibility of a decreasing rate of return (his 
Section 4) but did not carry it through to see the evaporation of the inevitability of an increasing capital share. He sees the decrease in $r$ as possibly threatening the inequality $r>g$, but accepts that the long-term prevalence of this inequality implies that the capital share 'a increases by definition' (p.522).

The inequality $r>g$ is not only insufficient to ensure an increasing capital share, it is also unnecessary. Taking the benchmark Cobb-Douglas again, it is clearly possible for capital accumulation and technical progress to be so high as to make $\mathrm{g}>\mathrm{r}$ and yet the capital share remains constant; a slight capital-using bias in technical progress than makes the capital share increasing with $g>r$. The necessary and sufficient condition for an increasing capital share is that the right hand side of (2) being positive, i.e. the combined rates of growth in capital and its rate of return being larger than g.

Related to but distinct from an increasing capital share, Piketty makes the following basic point incorrectly. 'When the rate of return on capital significantly exceeds the growth rate of the economy (as it did through much of history until the nineteenth century and as is likely to be the case again in the twentyfirst century), then it logically follows that inherited wealth grows faster than output and income. People with inherited wealth need save only a portion of their income from capital to see that capital grow more quickly than the economy as a whole' (Piketty 2014, p. 25). We may see the logical problem by showing that $r>g$ does not imply $\mathrm{dK} / \mathrm{K}>\mathrm{g}$ even if a positive portion of capital income is saved.

Piketty requires the rentiers to save only a portion of their income; even at a saving rate of only $0.01 \%$, capital is supposed to grow more quickly than income. This is very unlikely to be true for a substantially positive g and its inevitability even given $r>g$ is certainly untrue. Again, the excess of r over $g$ does not ensure a fast rate of increase in capital, nor the excess of this rate 
over g. It is totally possible under Piketty's requirements for $r$ to be quite high and well in excess of g, but for the rentiers to consume most of their income $\mathrm{rK}$, leaving only a tiny amount of saving. If non-capital incomes are also not heavily saved, total savings could be small, making capital $\mathrm{K}$ increasing at a rate much smaller than $\mathrm{g}$.

Consider first the case where non-capital incomes are not saved at all, a case not excluded by Piketty. Then capital incomes rK have to be saved $100 \%$ to ensure that $\mathrm{dK} / \mathrm{K}=\mathrm{r}$ that will ensure that capital grows faster than income under the condition of $\mathrm{r}>\mathrm{g}$. If we now takes account of saving from noncapital incomes, we again have the condition that, to ensure that Piketty is correct (that capital grows faster than income under the condition of $r>g$ ), the amount of savings from non-capital incomes has to exceed the consumption from capital incomes. This is a much stringent condition (but capable of being satisfied) than Piketty's condition of 'need save only a portion of their income from capital' (p. 25). Moreover, if the consumption of capital incomes have to be made up from the saving of non-capital incomes, the owners of future capital incomes will expand to include these savers of non-capital incomes, with implications for distribution or inequality that have to be taken into account.

\section{Concluding Remarks}

This note has refuted the inevitability of an increasing capital share (in income) under the Piketty-Milanovic requirements. However, it does not suggest the impossibility of this increasing share. In fact, Piketty has convincingly shown this for many major countries both for the recent decades and for the period after 
the industrial revolution but before the 'abnormal' period leading to the golden age of 1945-75. His argument that this increasing capital share will likely hold for the future may also be true. Thus, Piketty's analysis remains important and his recommendations to limit the increase in inequality may be highly desirable despite the logical blemish explained above.

However, the period leading to the golden age needs not be abnormal but may just partly be the result of capital accumulation. This accumulation leads to opposing forces affecting the capital share in different directions. In particular, the role of capital accumulation in raising the marginal productivities and hence incomes of non-capital inputs has not been given sufficient emphasis by Piketty. In combination with other forces like the direction of biased technical change, capital accumulation leads to decreasing capital shares in some periods, and to increasing capital shares in others, as Piketty has demonstrated with rich data for many major countries. It is difficult to say that a certain period is abnormal. To know how the future will turn out needs further studies and observations.

\section{Addendum}

I completed this paper in July 2014 (submitted to JEL then but it declined on 7 August to publish on the ground of long-standing policies of not publishing comments) without being aware of an earlier web paper commenting on Piketty by Ray (2014). I wish to thank Milanovic for drawing my attention to Ray's paper after I sent him a copy of my paper early in August. Ray also argues that $r>g$ is not sufficient for the increasing share of capital. Ray's paper thus shares this common criticism of Piketty with this paper (but I acknowledge Ray’s priority) but differs in at least three aspects.

- First, this paper uses the more precise Equation 2 in the text above for the necessary and sufficient condition for the capital share to increase (as well as a 
specific counter example of Table 1 and the benchmark case of the CobbDouglas production functions). On the other hand, Ray focuses more on the increase in inequality rather than the increase in capital share and hence emphasizes more the higher saving rates of the rich instead of Eq. 2 or its economic meaning.

- Ray concedes that Piketty is correct on the sufficiency of $r>g$ being sufficient for an increasing capital share when capital owners save all capital incomes. In Ray's words, 'Suppose that capital holders save all their income. Then r not only tracks the level of capital income, it truly tracks the rate of growth of that income as well, and then it is indeed the case that capital income will come to dominate overall income, whenever r > g.' (p. 4 of Ray 2014). The analysis of this paper (on the possible decrease in $r$ in particular) shows that Piketty is not correct even under this restriction of $100 \%$ saving of capital incomes. Thus, this paper goes further than Ray in this aspect.

- However, Ray goes further than this paper in arguing that 'the fact that $r$ exceeds g explains nothing about the rise in inequality' (Ray 2014, p.7). In contrast, this paper acknowledges: 'The basic Piketty-Milanovic intuition that the inequality $\mathrm{r}>\mathrm{g}$ is conducive to an increasing capital share is not incorrect; it is the sufficiency or inevitability ('by definition') of it that fails.' Thus, I would not go as far as Ray in saying that $r>g$ has nothing to do with or explains nothing about the rise in inequality, as explained below.

Ray is correct in emphasizing the role of different saving rates between the rich and the poor out of total income, capital or labor. He is also correct that inequality may either increase or decrease whether we have $r>$ g or $r<$ g. So in some logical sense, Ray is not incorrect. However, given the empirical facts that a very large proportion of capital income is owned by the rich and that the rich usually save more, then a large capital return $r$ and that $r$ is much larger than $g$ do 
make increasing inequality more likely, as also discussed in the text. Not only is a high $\mathrm{r}$ but an $\mathrm{r}$ larger than $\mathrm{g}$ is also relevant because a high $\mathrm{g}$ could reflect increases in non-capital incomes.

\section{References}

Milanovic, Branko (2014). The return of "patrimonial capitalism”: A review of Thomas Piketty's Capital in the Twenty-First Century, Journal of Economic Literature, 52(2), 519-534

Piketty, Thomas (2014). Capital in the Twenty-First Century, The Belknap Press of Harvard University Press, Cambridge, Massachusetts; London, England. Ray, Debraj (2014). A comment on Thomas Piketty's Capital in the Twenty First Century, May 23, 2014. Downloaded in mid August 2014. 